\title{
The Role of Identity of an Animated Character in the Story Line
}

\author{
DOI: $10.21625 /$ archive.v1i1.130
}

\author{
Soraia Mohamed Sobeih ${ }^{1}$ \\ ${ }^{1}$ Associate Professor in the Animation and Book Arts Section Graphic Department, Faculty of Fine Arts, Helwan \\ University
}

\section{Keywords}

Identity, Identity Crises, Animation, Animated Characters, Story Line.

\begin{abstract}
The identity of an animated character means who he really is, or what are the characteristics that would never change? How the character sees himself and how others see him? It includes shape, color, race, beliefs, and choices in life.

The more the storyteller gives identity to his animated character, the more it is sound and convincing. In that sense, it touches the audiences' hearts as they feel its pain or happiness. In other words, they are involved in the story and united with the character.
\end{abstract}

As the story begins, characters and settings are presented before the audience to get an overview of the characters' identity. Then, more elements are to show up, like the conflict, the problem that needs to be solved and the rising actions, which are series of events that lead to the high main point or the climax. It is considered as a turning point of the story after which the falling actions come. The falling actions are events and complications that start to loosen the plot. Gradually, the solution shows up as the story ends either happily or tragically.

Throughout the story line, these groups of events that form the story sometimes account for the appearance of an identity crisis that impacts the character. It means that he is uncertain of his feelings about himself; he gets confused about what type of person he is or what is the true purpose of his life. It always takes making an existential that plays a big role in the story line.

The identity crises appear in Toy Story 1995 to Buzz light-year when he discovers the truth of himself; that he is a toy, not a space ranger as he thought before. This made him give up hope of returning anywhere. It took him sometime to accept the fact of himself after seeing how Woody struggles to return them both to Andy. He tries his best to save his friend and return home safely, as being dictated by the role's vision.

In Toy Story 2 1999, the identity crises appear to Woody when Buzz strikes him with the fact that he is not a collector's item. He is a child's play thing, he is a toy. Then, a decision has to be made to return to Andy, and the struggles start with the Prospector.

In Toy Story 3, 2010, the identity crises appear to Woody at the end of the story. He was suffering to be away from all his toy family that will be left in the attic, so he wrote on the box to be donated and he attached himself in, with them hoping that Andy gives him a very warm goodbye and leaves him with the rest of the toys in good hands. 
In Finding Nemo 2003, the identity crises for Nemo is when he chooses to touch the boat, even though it is a dangerous thing, just to prove to his father and his friends that he is brave. It led him to fall in the capture and to meet other fish Gill in the tank which gave him confidence in himself and made his personality and identity clear.

In Ponyo 2008, the identity crisis appears when Granny asked Ponyo if she was ready to give up all her super powers in order to be a human living with Sosuke on earth. The answer was "yes", and then she fulfilled her dream even if it seemed strange and felt happy ever after.

In Astroboy 2009, the identity crises for Astro is when he discovers that he is not a real boy, so he runs away and tries to discover his true identity as a robot. He took his great decision when he refuses to fight other robots especially Zog, which led at the end, to rescue him from the same positive power he had given to Zog before. He finds his true identity as a hero that fears nothing and protects humans.

In Big Hero 2014, the identity crises for Baymax takes place when he decides to give up his own life and existence in order to save two humans, Hiro and the Astro girl. He raised his hand to provide them with power that could navigate them to the gate. Sooner, we were surprised to find the chip lift in his hand, so Hiro could restructure him, and this plot twist is what gives the story cohesion and enchantment.

\section{IDENTITY}

Finding our identity and place in the world is something we will, inevitably, have to face in our lives. Identity is whatever makes an entity definable and recognizable; it is the person's self-affiliation (or categorization by others) as a member of a group. Others defined it as the feeling of belonging to a group. Identity holds that nature of being part of a person's self-conception and self-perception, and it is related to nationality, ethnicity, religion, social class, generation, locality or any kind of social group that has its own distinct culture. 1

An identity is the set of meanings that define who a person is when it is an occupant of a particular role in society, a member of a particular group, or claims particular characteristics that identify him or her as a unique person2. For example, Identity is the way we perceive and express ourselves. Factors and conditions that an individual is born with often play a role in defining the one’s identity; however, many aspects of a person's identity change throughout his or her life. People's experiences can alter how they see themselves or how others perceive them. Conversely, their identities influence the decisions they make, like individuals choose their friends, adopt certain fashions, and align themselves with political beliefs. Accordingly, many artists found solace in using their work to express, explore, and question ideas about identity. 3

The identity of an animated character is defined as a building block of the personality of a character in a way that connects it with the surroundings. It lets the audience feel the character's characteristics, his motives, and his fearswhich are derived from him- that gives him credibility and trust. When a great decision is to be taken by the animated character, this causes what is called an identity crisis, and in most of the cases, it is at the peak of the story line. It takes time and thoughts to be shaped. Then, the character makes up his mind and takes the decision, which will change his course in life, fulfill his dream and brings happiness to his life. Sometimes, he chooses to sacrifice himself to save others.

\section{The Story Line}

It is the series of events that happen in the story. Having unique plot is what allows the story to shine and rule. A plot is the sequences of the story's events. It begins with the Exposure as a start to introduce the characters, then the Ascending Actions that lead to the Climax, which has one or more problems making a high point of the story. The Descending Actions are when the tension decreases and everything begin to settle down. After that comes the Resolution, which makes the Ending and gets the conflict solved.

Pixar explores the thematic concern of identity throughout many of their films; it demonstrates how its characters struggle to find their identity. It is the idea of an identity crisis of the main character that is torn between the demands of his group identity and his own aspirations, ambitions, and dreams.

1 www.wikipedia.com

2 Identity Theory By Peter J. Burke; Jan E. Stets, Oxford Press

3 www.moma.org 


\section{Toy Story 1995:}

Woody has been Andy's Favorite Toy for a long time, an Andy has played with Woody the most. He wears a hat like him and decorates his room like the Old West drove from the American culture. Woody is the leader of Andy's room, for he has good leadership skills. He knows how to plan and motivate other toys and he can put himself at risk to for a greater cause, like risking Buzz and himself from their most fear of being lost. In addition, he tries to reclaim their owner “Andy”, and he would never give up on Andy.

Buzz believes he is a real space ranger, his mission is to save the galaxy from the evil of Zorg. He even does not believe Woody when he tells him that he has no laser! he cannot really fly! In addition, he is not a real space ranger; he is a child's plaything! He is just a toy (Fig.1). When Buzz sees the toy commercial and discovers that his inability to fly, he suffers a severe identity crisis. For once, Buzz does not know who or how to think about himself (Fig.2).

At this point, we feel connected to the suffering and disappointment of Buzz not knowing who he really is. We tend to feel lost and unsure about our identities. He surrenders to despair to the extent that he asked Sid to blow him with a rocket. Fortunately, Woody convinced him that he has a big role in life as Andy's toy. He must fight to go back to him, so after his identity crisis culminates in a resolve to "Be" Andy's Toy, Buzz must think of ways to fulfill this new identity. He also tries to help Woody to escape from Sid and go back to Andy4.

Accepting Buzz for his identity, believing in his purpose of life as a toy was a high point in the rising actions just before the climax of the story. In other words, they were trapped, Sid woke up going to launch the rocket, and the van was moving and Andy was leaving. It led to the solution as Woody has planned to liberate Buzz. Woody and Buzz manage to return to Andy's car, and then to reconcile afterward. Luckily, Woody was re-accepted among the other toys, and he was sharing the same status favorited by Andy and Buzz.

\section{Toy Story 2 Pixar, 1999:}

As we see Woody's journey, and the challenges he faces with his identity, he comes across some new characters, Jessie and Prospector; who are part of the set of television tie-in merchandise, which Woody originally belonged to. 5 They offer him a very hard choice between immortality and love. That is, he can live forever in a museum in perfect condition with his "natural" toy family. Alternatively, to accept his own mortality as the price of Andy's love, yhis becomes a real dilemma for Woody as he struggles with his own identity and his true purpose in this world.

“Woody, you're not a collector's item. You are a child's play thing. You are a TOY!”, that’s what Buzz Light-year told him6, and this matter of identity was the same thing that Woody was trying to explain to Buzz in the first part to make him understand that he is Andy's toy and should act like a family member. Woody tries to decide what is more important to him; his immortal and natural destiny of being with his family of toys; or, to re-join the family he grew up with to serve as Andy's toy. He, of course, choses to return to his beloved Andy and see him growing even if that was leading to neglecting him or not being played with after Andy grows up and gets older.

This was the identity crises for Woody. The big decision that he made and that explains who he really is, he is Andy's toy that is the main and the most important thing in his life and he would not give it up for any reason or anything in the world. He must always be there for Andy as long as it takes. This big decision led the audience into more unity and sympathy with Woody, we find ourselves connected with him in his struggle with the prospector to go back home (Fig.3), even Jessi changes her mind and determines to go with Woody to be part of the toy family with Andy's sister. Taking big decisions, rethinking, changing our minds are all human characteristics that when we put them in our animated characters we feel connected to them and we tend to believe them.

\section{Toy Story 3, Pixar, 2010:}

Andy is a teenager heading to the college, and Woody faces the same identity crises once again, he has to choose which is better: to stay in the attic as long as it takes or to go away to a nursery to have other kids to play with. In fact, all the toys face the same identity crises they choose the nursery, but Woody does not as his true self is a friend of Andy and he never let go of him.

\footnotetext{
4 http://dramatica.com/analysis/toy-story\#os

5 www. Pixar animation weedly.com

6 Robert Velarde; The Wisdom of Pixar, An animated Look at Virtue, IVP book
} 
He stands for Andy and makes his friends, Jessie and others, see that they have to stay Andy's toys for as long as it takes. He wanted to show them that it is his decision to keep them in the attic or to be donated to someone. It took part in the ascending actions of the story. Therefore, first, Woody decides to stay in the attic and not to run away as the rest of the toys did. Moreover, he made it his duty to convince them to return back with him.

As the second identity crisis emerge, he decides to stay with his toy family and not to be separated from them (Fig.4). When he got into the box with them, Woody helps Andy to see that Bonnie that it is a good choice to donate his toys. Surprisingly, we were shocked to find Woody with them in the box after they all faced death in the junk big fireplace, as he sees himself as part of Andy's toys family and decides to stay with them.

It has been so hard for both Woody and Andy to be separated, but that's life. He keeps all his love for Andy, but with after reconsideration, it was really better for him and for the rest of the toys to stay with someone young and gentle, like Bonnie. We felt his suffering and thinking when the toys were saying goodbye to him before getting into the box at the falling actions of the story. It was a sad moment. Such scene creates solid bonds between the audience and the character. Another sentimental scene occurred when Andy was giving the toys to Bonnie, describing the characteristics of every one of them especially Woody, saying that he will always stand for her as she did for him. Practically speaking, we sometimes find ourselves forced to be away from someone who is very special, like when a dear one travels to study or work. We feel sorry but we continue our lives carrying all the love and good memories we had and looking forward to the future and the good that it brings to us.

Another case is Remy in Ratatouille; he felt, dreamt and knew he would be something more than just a rat eating garbage but he would be a chef, so he pretended to be a rat for his father. Teamed with Linguini, he can fulfill his dream of cooking. He had to pretend that Gusteau existed to have someone to talk to. Ultimately, we realized his identity to be a chef doing what he dreamt of and still is a part of his beloved family.

\section{Finding Nemo, Pixar, 2003:}

The identity matter derived from Nemo's will of learning, exploring and discovering is formed not only because his father Marlin prevented him. The most important aspect is how Nemo struggles to gain knowledge and adventure. The identity crises for Nemo appears just as the beginning of the ascending actions of the story when he chooses to touch the boat (Fig.5) His crusade was to prove his father and others that he is brave and he is capable of doing more things than it seems. It led him to fall in the capture captured of bullies, and a fish (Gill), who gave him confidence and trusted his abilities unlike his father, also led to the finding process that is the core message of the film.

Nemo had to go through a tedious process of discovering himself and understanding his abilities in the ocean. A true manifestation of that happened when he put a rock in the fan to make it stop. This understanding of one's abilities makes him understand himself. He succeeded to prove everyone and himself he could swim to the boat, but he discovered that his father was right and it is a dangerous thing to do. Such action led the audience to sympathize with the little fish. We understand his desire to improve himself as he has a disability in his small fin, so we feel more connected to him.

After Marlin met Dory, he learnt to trust others even if they lacked some abilities. If Dory keeps on forgetting, but she can read, speak whale, she still has good instinct and good manners. She helped Marlin all through his journey and never gave up on him. Through the journey, Marlin faces all his fears, sharks, crabs, and birds. He even became courageous, trusty and more confident.

The ocean is the setting for this little fish tale, it is not safe, but it is also a magnificent world of colors, beauty, and life. There are different kinds and schools of fish swimming together7. It is a magical place where love and friendship could be found in the darkest places.

The climactic scene occurred in the dentist's office. Nemo was playing dead to escape the place when Marlin was about to arrive. We know that Nemo was faking it, but his dad was not (Fig 6). We understand the stakes in this scene, but Marlin and Nemo do not have the full picture yet. With Gill's help, he puts Nemo into the water to catch his dad who swam hundreds of miles looking for him to be finally reunited again. The journey changed both the son and the father. Marlin learnt to trust his son and make him try things and decide for himself. In addition, Nemo learnt that it is fine that his father loves him and cares about him, but this care should never prevent him from discovering the world and living his own life.

7 http://www.shmoop.com/finding-nemo/ocean-symbol.html 


\section{Ponyo, Ghibli, 2008:}

Ponyo is a mesmerizing goldfish, who lives with her sisters in the undersea kingdom (Fig.7). Her dream is to explore the human world; she does and falls in love with Sosuke, a nice human child, whom she determines to spend her life with, regardless of any events that would ensue her decision.

The Identity crisis appears when Ponyo was asked by granny if she is ready to give up all her super powers in order to be a human and live with Sosuke on earth or not. Her transformation into a human upsets the balance of nature 8 and causes Tsunami. Her answer was yes, so granny puts Ponyo in a bubble and gives her to Sosuke to complete her transformation by kissing the bubble. She kisses him back and then she got transformed into a real human girl (Fig.8). She can always visit her sisters in the ocean, but as a human not as a fish. She fulfilled her own dream even if it seemed strange and unique. Most importantly, she felt happy by this change.

The decision made by Ponyo was a crucial one that affects essential changes in her lives on different levels. She will continue her life as a magic fish girl with magical powers in the ocean with her sisters, or she will lose her magical powers to become a human girl living on the shore with her friend Souske. There were other concerns of the environment that were affected by Ponyo's switch that made a tsunami, but it calmed down after she took her decision and gave up her magic powers. There was no reason presented before to understand this change except her will for that, and after she made up her mind, she felt happy.

This identity matter or big change /decision made the audience feel her opinion and believe her childish desire to be with her friend. She tried the life of humans before and enjoyed it, but as a magic fish through the beginning and middle of the film, yet the big decision came at the descending actions before the end to pave the way for a solution to appear.

Both the ocean and the land are the settings for this magic fish tale, but it differs than Nemo's as its made in a 2D form, and water colors are used in the backgrounds. Also, the anime style in drawing the characters and the small actions reminded us of the humanity of Myazaki's characters and the magnificent world of color and beauty. Also, the relationship between man and nature9 that forms a main concept in the Anime movies. We can say it is the true love and friendship between Ponyo and Sosuke.

Usually, the Japanese animation uses a cinematic fabric more similar to a live action film in the United States. As for adults, the action-oriented narratives, and true character development are over a well-paced time frame. All of the aforementioned details are not typically found in a typical American animated feature. Everything that is created has a visible spirit, which could be traced back to some aspect of its creator who is in return exemplifies some unit of a culture.

\section{Astroboy, Summit, 2009:}

The head of the ministry of science, Dr. Tenma, creates a powerful android to replace his son Tobi (Astro Boy) who was killed. Unfortunately, his creator rejects him, and that led Tobi to go off in order to find his own identity in an adventure that would make him his time's greatest hero10.

The first identity crises for Astro happened when he discovered that he is not a real boy, and that caused him grievances. The feelings of being lost and not knowing the one's place in the world made connections between Astro and the audience who felt he suffer and loss. It united them with the character in his search for his own identity. Similarly, in real life, we sometimes search for our roles in life. He managed to be a part of the human race, and along with his friend, they fix Zog, a big robot. Astro takes his big decision when he refuses to fight other robots especially: Zog, the one he had helped before, showing that they are not just made from metal but they also have feelings.

The second identity crises is when he decided to sacrifice himself (Fig.9) to face the negative red energy with his own positive blue one just after the climax of the story reveled when the red bad energy was out of control and threatening all the city, as this was the only way to confront it and save the city. This action led to several things in the story;

\section{Blaster. com}

9 www. Apjjf. org/2014/12/39/ Hiranmoy- Lahiri /4191/article.html

10 www.imdb. com 
1- The negative powers vanished, and the villain disappeared.

2- All the people in the city were saved, and the saw how heroic the Astro boy is, and how much the cares for humans (Fig.10).

Zog the big robot helped him.

3- His father, Dr. Tenma, realized that he should treat robots better and he should accept his new Tobby (Astro boy) as he is; a robot with the heart of a lion and a hero ready to face fears and defeat all kinds of enemies.

4- Astro boy himself discovered his destiny and identity: to love his father and his friends, and to accept being a different robot, one of a kind with big heart born to be he

\section{Big Hero 6 Disney 2014}

The special bond that developed between robot Baymax, and Hiro Hamada, who team up with a group of friends to form a band of high-tech heroes. 11

We can recognize the identity of East Asia, which is represented in the Anime style, which Disney borrowed. When the Big Hero was under production, the original story was done after the nuclear bombing of Nagasaki and Hiroshima12, but Disney added some tweaks to the story to fit also the American society. Hiro loses his brother, and the unlikely friendship between a boy and his robot the film borrows from Japan's culture. It runs in a country called San Fransokyo, a mix between Tokyo and San Francisco. A busy crowded city full of inventions and it has under cover super heroes. The city has scenes, like the twisted roofs of houses, the very tall skyscrapers, the flying kites, and the high tec. The Design of the characters made a combination between the American and Japanese cultures in a modern look.

The Identity crises in big Hero happens when Hiro faces the villain, who killed his brother Tadashi and decides not to harm him as he was willing to do in the first time, but instead of delivering him to the police to take what he deserves by low. Although it was hard for him not to take revenge for his brother, it showed what he truly is, a good kid that cannot harm anyone, and that is his true identity. He is an inventor that delivers goodness for the humanity and cannot harm any of them even if he is an evil. The scene that led to that was when Hiro saw the records of his brother in Baymax. He was very anxious to save and heal tge people by checking and stabilizing their health.

The other identity crises for Baymax himself is when he decided to sacrifice himself, his own existence in life, to save two humans; Hiro and the Astro girl. He waved his hand to give them both power to return to the gate and to be rescued. In this moment, the audience felt Baymax's love and sacrifice. They got connected with him and felt Hiro's fear of losing his friend, the one he loves after he had lost his brother before. All these emotions drive the audience to be connected with the characters in order to believe them.

This identity decision is driven by Baymax's belief that his very special role in life is to help people become in a good condition. His revolutionary decision came after the climax of the story as they confronted the danger, the scientist who stole the robotics and destroyed everything. So, it was in the descending actions driving to a dramatic ending except for the happy surprise to find the chip in the hand. Hiro built another Baymax and that was a happy ending.
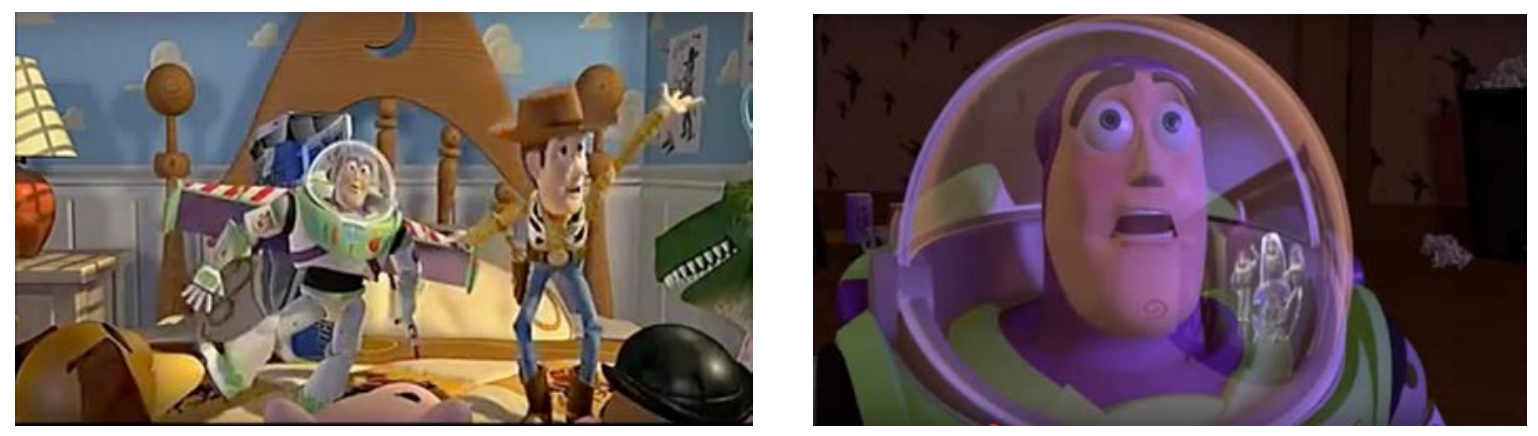

11 Imdb.com

12 http://www.theverge.com/ 


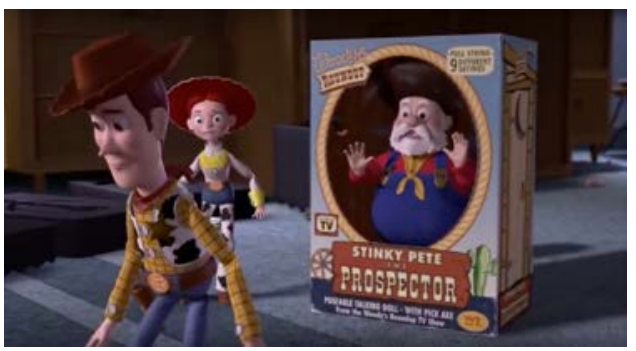

Figure 3.Woody decides to go back to Andy

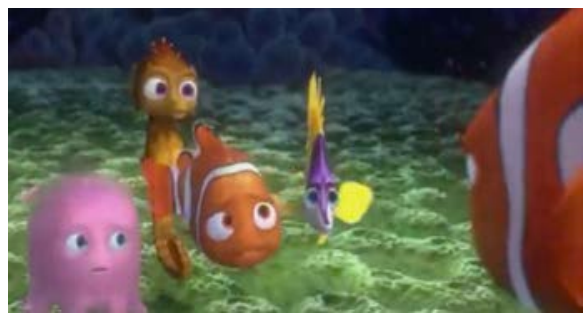

Figure 5. Nemo decides to touch the boat

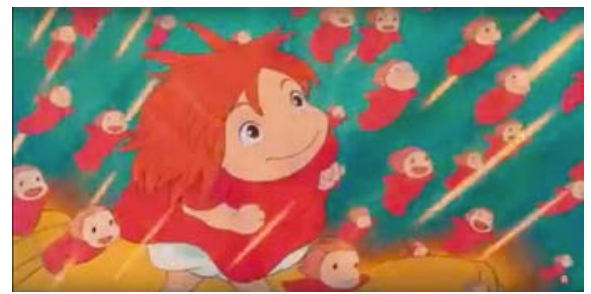

Figure 7. Ponyo swims dreaming to live on earth

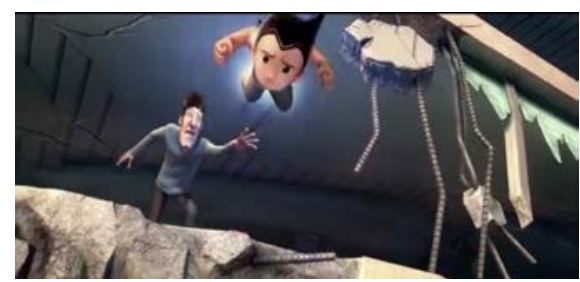

Figure 9. Astro going to save humans defeat the evil robot

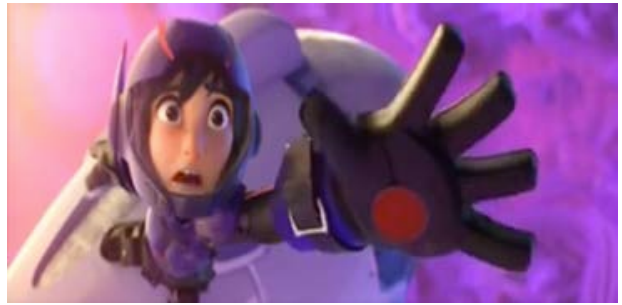

Figure 11. Hiro trying to grab Baymax to save all

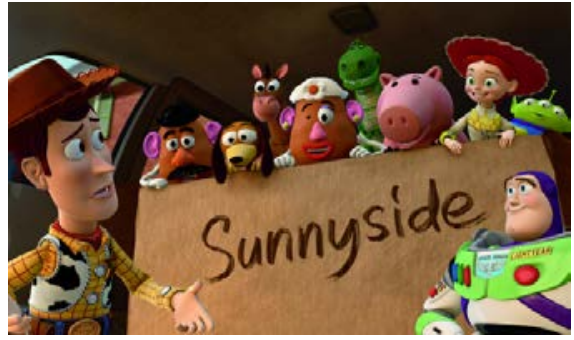

Figure 4.Woody is thinking to stay with his friends

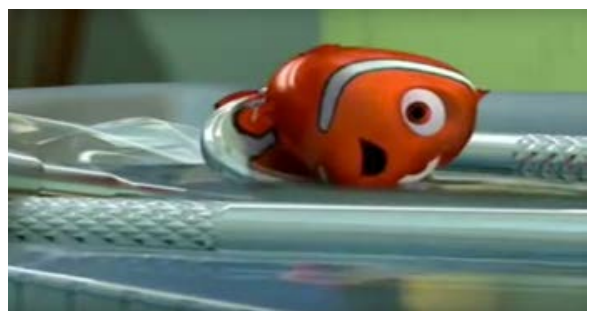

Figure 6. Nemo is playing dead at the dentist's

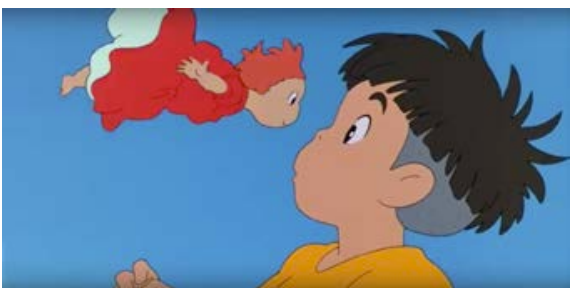

Figure 8. Ponyo transforming into a human girl

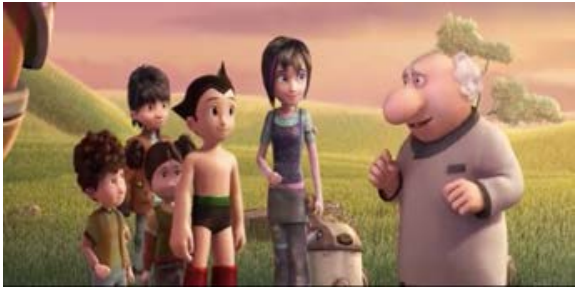

Figure 10. Astro with friends after reveling his identity

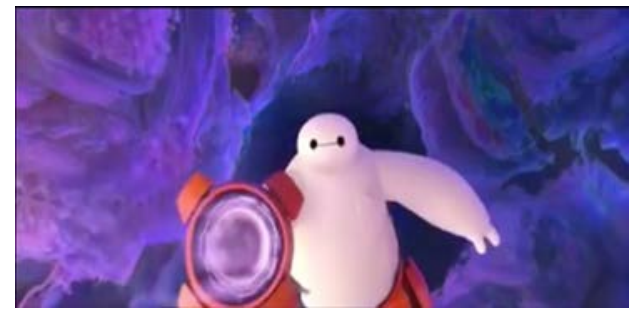

Figure 12. Baymax sacrificing himself to save his friends

\section{Conclusions:}

We give our animated characters human characteristics, we design their identities and personalities to express feelings and make the audience united with them.

Like humans, the animated character can come to a point in the story where he is not sure what to do or which option to settle on. In doing so, it will have a big impact on his life and on the story line after that decision, and that we can call identity crises. 
Unregular decisions taken by the animated character could take some courage and think but always lead to pleasure and satisfaction of the character at the end because he discovers his true identity through his believes and dreams.

In Toy Story, accepting Buzz for his identity, believing in his purpose in life as a toy was a high point in the rising actions just before the climax of the story that is Woody's plan to free Buzz and reaching the van

In Nemo, when he chooses to touch the boat even though it's a dangerous thing, to prove that he is brave and he is capable of doing more things than it seems, led to the missing process that made Marlin took the journey to find him, I think this was the first main point in the rising actions.

In Ponyo, she began testing human life till she took the decision of completely transforming into a human that was just before the conclusion, or the solution of the story as she made up her mind and felt happy ever after.

In Astro Boy, two important identity decisions were made, the first minor one not to fight robots, the second to conflict big negative power with his own to save humans this was one point after the climax of the story as a beginning of solving the problem how to face this bad negative power and that led to Astro knowing his true identity as a hero who fears nothing and cares for humans.

In Big Hero 6, when Baymax decided to sacrifice himself to save Hiro and the astro girl this was after the climax of the story as they defeated the big danger, the scientist who stole the robotics and was destroying everything, but then remained one thing to be done that was saving the girl and returning back safe so this was in the falling actions driving to a dramatic ending except there was one big twist that led to a happy ending.

\section{References}

1. Peter J. Burke (2009), Jan E. Stets, Identity Theory, Oxford University Press,

2. Harris Williams (2013), Animation, Globalization and Cultural Identity, Master, SVA, USA

3. Robert Velarde; The Wisdom of Pixar, An animated Look at Virtue, IVP book

4. Lim, T. W. (2017).50 Years of Singapore-Japan Relations. World Scientific Publisher.

5. Miller, G. E. (2014, November 01). How anime inspired Disney’s ‘Big Hero 6’. Retrieved August 30, 2017, from http://nypost.com/2014/11/01/will-disneys-japanese-anime-big-hero-6-get-lost-in-translation/ 